\title{
Mathematics Education Research Food For Thought With Flavours From Asia
}

\author{
Allan Leslie White \\ University of Western Sydney, Australia. \\ $<$ al.white@uws.edu.au>
}

\begin{abstract}
This paper will dip into the wonderfully rich, internationally flavoured, mathematics education research smorgasbord. In more recent times the focus has concentrated upon the cook (the teacher) and the skills needed (pedagogical knowledge) to produce delightfully pleasing brain food to nourish the growth of students. However, if this focus ignores the other essential ingredients (context, students, parents, and policies) then the results do not meet expectations. These expectations are also many and varied and include academic standards and achievement, engagement and deep understanding, exciting and enjoyable teaching and learning, relevant and meaningful learning, and the development of thinking and reasoning skills. Mathematics education research is a source of many recipes for success, and where the various countries provide their own cultural flavours. This paper will attempt to provide a taste of a range of samples drawn from research in order to satisfy an assortment of expectations while providing food for further thought.
\end{abstract}

Keywords: mathematics pedagogical repertoires, glocal, cognitive challenge, brain research

\section{Global Movements in Food and Mathematics Education}

Food is essential for humanity to survive and it is truly amazing to consider the enormous variety of food and ingredients that are used across the globe. The variety of food eaten usually reflects aspects of the climate and culture, and this also applies to the cooking styles and the combination of ingredients. As the world has become a global community through the advances in technology and communication, this has also lead to the different food styles and recipes spreading throughout the world. In my own suburb of Sydney Australia, which is near a large international university, I counted twenty-three restaurants offering food dishes from other countries. Currently my television stations offer many shows involving travel cooking by some Australian celebrity cook going into another country. For example 'Luke Nguyen's Greater Mekong' or 'My Sri Lanka with Peter Kuruvita', are only two of many shows that include game format cooking shows as well such as 'Master Chef, Junior Chef' and so on. The reason for focussing on food and cooking is to make a comparison. When we compare the spread of food and cooking styles with the spread of mathematics education styles of teaching and learning, it raises some interesting similarities and differences.

If we consider the global food movement, while we often compare different dishes or recipes, we usually do not get too excited at trying to rank which is best nor do we decide to adopt a recipe from another country and throw away our own well-loved dishes. Instead, we get excited about the rich diversity that these new dishes offer, which according to our tastes, we incorporate certain ingredients or cooking styles into our own to improve or provide 
greater variety to our own dishes. Imagine the shock at home if we decided to totally adopt the Japanese cooking style and diet and discard our own.

Why is it that the mathematics education movement seems to do the opposite of what I have described about the global food movement? Why do education authorities and government bodies expend so much energy in ranking countries using international comparison examinations such as TIMMS and PISA? Especially since research has shown these tests to be invalid when comparing countries. In Australia, the current government has introduced a National Assessment Plan in Literacy and Numeracy (NAPLAN) in response to a perceived drop in performance. The teaching community has complained that the testing narrows the curriculum and interferes with the learning cycles of school. The teachers want the many millions of dollars directed to programs that improve student outcomes, not just measure them. Surprisingly the Australian government seemed to be ignorant of the fact that the drop in performance had more to do with changes in the demographics of the sample chosen than changes in the general achievement performance of the children. So it seems that these tests can cause harm when they are not used in a measured and considered fashion.

However, these tests can be very useful, and teachers have adapted and used items in their teaching and the video material of classrooms in different countries has been extremely informative. Watching an Indonesian, German or a Malaysian teacher in the classroom is very interesting and informative and different aspects can be modified and adopted into Australian classrooms in the same manner as watching an Indonesian cooking show on television.

So it is how the international comparison test items and results are used that is the problem and ranking countries is both problematic and unfair.

\begin{abstract}
International studies of mathematics achievement have profound influence on mathematics education worldwide in the past 15 years. Results of studies such as TIMSS and PISA have dominated the agenda of discussion in the mathematics education community as well as among policy makers. Much attention however has been paid on the ranking of countries in the league tables generated from such studies, often without due consideration of the nature of these studies, as well as the contextual factors that affect the performance of students from different countries (Leung, 2012, p. 34).
\end{abstract}

I find it very heartening to observe that the Southeast Asian Ministers of Education Organisation (SEAMEO) through their regional centres of excellence such as the Regional Centre for Education in Science and Mathematics (RECSAM) in Penang, Malaysia, and the Regional Centre for Quality Improvement of Teachers and Educational Personnel (QITEP) in Yogyakarta Indonesia are developing their own examinations and it is hoped they will learn from the mistakes of the other studies.

Consider one more illustration concerning the global movement of food compared to mathematics teaching and learning. A Japanese recipe for sushi would be adapted in Australian home kitchens using local rice, fish, sauces, and although it would be similar to the Japanese dish, a Japanese person eating it would notice differences. Compare this with the 
spread of Japanese Lesson Study. Japanese Lesson Study spread throughout the world and particularly across the Asia Pacific region and it has had a global influence upon the teaching of mathematics. The spread of Japanese Lesson Study has received support through the growth of information communication technologies and the ease of international travel. For example, the World Association of Lesson Studies (WALS: http://www.worldals.org/) was formed and this promoted Lesson Study at many levels from systems to individual schools across a range of countries. Another project, one which was supported by the Asian Pacific Economic Cooperation (APEC: http://hrd.apecwiki.org/index.php/Lesson_Study\#Lesson_ Study_inMathematics), was designed to encourage the spread of Lesson Study across the region. There were admirable projects but the problem was in how this spread was adopted, with some countries adapting it to their educational, cultural and social contexts and others trying to make an exact copy.

Nowadays, most packaged food contains a list of ingredients and warnings about possible food allergies. Regarding Japanese Lesson Study, there were warnings from Japanese scholars against trying to copy exactly their model to other countries.

When thinking about the global issue of improving the quality of education, Lesson Study, which has a dialectical relationship with the theories and practices employed on the front lines of education, must be versatile enough to be applicable beyond the Japanese context" (Baba, 2007, p.6).

Yet in spite of these warning there were attempts to copy exactly the Japanese Lesson Study model into other systems, and some attempts even imported Japanese teachers but the results were unimpressive. It seemed that those countries that used a 'glocal approach were more successful (White \& Lim, 2008).

The term 'glocalisation' was constructed to explain the process whereby the global and the local influences interpenetrate each other, creating a hybrid model. This hybrid contains sources of global trends adapted and blended with local conditions and options. In other words, global trends are contextualised by the specifics of the local settings. In terms of food, foreign recipes are modified to cater for local tastes and ingredients. In a global world there is increasing pressure to use and adapt successful mathematics teaching and learning practices from other countries. However, the dangers of adapting these practices require consideration of both the practicality of technical implementation and the extent to which the beliefs underlying the adapted practice resonate with local cultural values.

To summarise this section, a brief comparison between global food movement and the teaching and learning of school mathematics revealed that both were experiencing similar global influences through greater exposure and communication due to improvements in technology but differences were evident in the reactions to these influences. In the rest of the paper, the food metaphor will be used to further highlight some of the current issues facing the teaching and learning of mathematics. 
While food and exercise are needed for a healthy body, the brain requires stimulation, challenge and exercise if it is to stay healthy. As a result of brain research, we no longer regard the brain as a fixed organ. Research has shown that the brain can reorganise itself. Neuroplasticity was the term given to the remarkable ways in which the brain adapts and transforms itself as a result of a change in stimuli. Brain researchers showed that:

\footnotetext{
Children are not always stuck with mental abilities they are born with; that the damaged brain can often reorganise itself so that when one part fails, another can often substitute; ... One of these scientists even showed that thinking, learning, and acting can turn our genes on and off, thus shaping our brain anatomy and our behaviour (Doidge, 2008, p. xv).
}

In the next section, the paper will consider if the correct brain food is being delivered by some common teaching strategies, or whether students' brains are being starved through lack of stimulation, challenge or exercise.

\section{Are You Starving Your Students?}

For many school students, mathematics is more like eating Brussels sprouts or broccoli; they know it is healthy and good for them but no one wants to eat it. Why is this true for mathematics when for cooking a good cook can easily modify the recipe and methods to overcome the taste of the unloved ingredients? Why can't many mathematics teachers do the same? Prominent researchers have criticised the brain food being dished up in some mathematics classrooms and pre-teacher education courses:

\footnotetext{
There is an urgent need to change school mathematics and mathematics teacher education in fundamental ways... Old patterns and methods are so deeply entrenched in many schools and teacher education institutions, and particularly in the minds of teachers, lecturers and students, that there is an urgent need to problematise existing practice and equip and empower practitioners to achieve change. (Clements, 2003, p. 638)
}

While many school mathematics teachers work very hard and are very dedicated, and many of their classroom strategies are nourishing for young minds, nevertheless Clements was deeply disturbed by what he regarded as serious examples of cognitive undernourishment. He made use of Brousseau's (1984) didactical contract construct (Clements, 2004) to illustrate the issue and a deeper treatment of this can be found elsewhere (White, 2011). What follows is just a brief summary.

Brousseau (1984) drew attention to how a teacher's intervention could reduce a student's role to answering a series of relatively simple questions, by 'emptying' the task of much of its cognitive challenge for the students. Cognitively challenging questions were removed from the menu and replaced by bite-size portions (I will call it baby food). The seduction of behaviourism that promotes mastery learning and 'breaking a long journey into small steps' was evident. When teachers adopt this style of cognitively emptying the task of challenge and break it into a number of smaller steps, in an attempt to help students tackle 
higher-level mathematics tasks, they deny their students the opportunity to formulate and apply strategies of their own (Clements, 2004). If this becomes the predominant classroom teaching strategy then the students are starved through being fed mathematics emptied of any goodness and cognitive challenge. They are served small portions that are easily chewed and digested and totally leave out the mathematical solids that would challenge the brain. Examine the following dialogue.

Teacher: Add one half and two thirds

Student: Cannot

Teacher: Ok multiply 3 and 2

Student: 6

Teacher: Good write that down at the bottom of a fraction, now what is 1 by 3 ?

Student: 3

Teacher: Good write that on top of that fraction to make a half, and what is 2 by 2?

Student: 4

Teacher: Good write that on top of that fraction to make two thirds, now add 3 and 4

Student: 7

Teacher: So write 7 over 6, now write it as a mixed number

Student: One and one sixth

Teacher: Very good, understand?

Student:Yes.

Skemp (1976) using his distinction between instrumental and relational understanding, would classify the student's understanding here as instrumental. While the teacher's intentions are kind and helpful, good intentions are not enough. The teacher also makes an assumption that if the student answered each step, then the student had learnt what had just been taught, and the student could construct the whole from the parts thus the student should be able to add two fifths and one third following the same procedure. Of course not every student could and the retention by the students was very poor. The strategy of cognitive emptying has been shown by a large number of research studies to produce poor results and students' were often unable to apply this learning to other novel problems. Imagine serving baby food to teenage school students, they would probably spit it back at us. Perhaps that is what is happening in mathematics lessons which serve 'chopped up muck'.

Brain research provides an alternative and helps explain the poor results of this teaching strategy and why mathematics teachers are often frustrated when students are able to solve problems or use a procedure correctly one day but cannot remember how to do the same things on the next day because the brain treats it as new. The reasons are:

Students may diligently follow the teacher's instructions to memorize facts or perform a sequence of tasks repeatedly, and may even get the correct answers. But if they have not found meaning by the end of the learning episode, there is little likelihood of long-term storage (Sousa, 2008, p. 56).

So in the dialogue presented earlier, unless the students has formed some meaning from the teachers instructions, then the teachers instructions will not be remembered. For 
longer retention, the teacher needed to help the student with the concepts of fractions and addition of fractions rather than just with the procedures to get the answer. Conceptual change remains one of the most essential outcomes of learning. It is an intentional and constructive effort to bring about deep understanding. The fact that some teachers have to do so much revision and student cramming before the end of year examination points to the methods of teaching and the lack of help to students trying to make meaning. Instead the usual outcome of this cramming process is to blame the poor results on the intelligence of the students.

We will examine another poor example of teaching before looking at some good and successful ones, and examine their ingredients of success. There are many examples reported in research of strategies that reduce the cognitive challenge and high level thinking of the students by stifling discussion and over emphasising drill and practice.

It has been stated that drill and practice are the rice dishes of Asian mathematics classes. While it is common for many Asian meals to have rice as one dish, it would be highly unusual to have a meal of only plain rice and no other dishes of vegetables, fish, or meat. A single plain rice dish diet would quickly become boring and lead to poor health. Some mathematics teaching strategies are used like a diet of single rice and result in bored students who are sick of mathematics. For example, after viewing the TIMMS videotapes of Australian Year 8 mathematics classes, a widely respected mathematics educator, Alistair McIntosh was moved to make the following comment:

\footnotetext{
What overall picture [do the lessons] give of a typical Year 8 Australian lesson? The teacher talks a lot, the students mainly reply with very few words, most of the time the students work using only pencil and paper, on a repetitive set of low level problems, mostly presented via the board or textbooks or worksheets, discussion of solutions is mainly limited to giving the right answer or going through the one procedure taught. There is little or no opportunity for students to explain their thinking, to have a choice of solution methods or to realise that alternative solution methods are possible; and very few connections are drawn out between mathematical ideas, facts and procedures (McIntosh, 2003, p. 107)
}

Where is the intellectual challenge? Where is the brain food? Where is cognitive stimulation? How are students supposed to develop thinking skills and construct meaning in such an environment? This seems to be a classic case of cognitive starvation, and it would not be surprising if these students were disengaged with mathematics and gave up study of the subject at the first opportunity.

Luckily not all teaching strategies lead to cognitive starvation and some actually promote the development of thinking by increasing the level of cognitive challenge. There is a crucial distinction between a strategy that empties a mathematical problem of challenge and a strategy that gradually increases the level of challenge presented to the students by differentiating the curriculum and catering for individual needs. 
A classical education of the nineteenth and early twentieth involved learning other languages which strengthened auditory memory, precise handwriting that helped strengthen motor capacities which added speed and fluency to reading, and an emphasis on correct speech and pronunciation. As a leading brain researcher states:

... for hundreds of years educators did seem to sense that children's brains had to be built up through exercises of increasing difficulty that strengthened brain functions (Doidge, 2008, p. 41).

Amazingly, cognitive exercises (brain food) have been designed by brain researchers and trialled that have improved memory, problem solving abilities, and language skills in mature aged subjects and children, reversing the aging process by twenty to thirty years in some adults. These exercises have also been used with autistic children with amazing effects on their language skills and autistic behavioural traits.

For example, Fast For Word is a brain training program consisting of seven brain exercises. It has had remarkable success with language-impaired and learning-impaired children including autistic children. The program which is a series of plasticity based techniques

... have helped hundreds of thousands. Fast For Word is disguised as a children's game. What is amazing about it is how quickly the change occurs. In some cases people who have had a lifetime of cognitive difficulties get better after only thirty to sixth hours of treatment (Doidge, 2008, p. 47).

So in considering the question of cognitive starvation, it has emerged that the need for challenge, construction of meaning and rewards are important for nourishment of the brain. An easy reaction is to blame the cook or teacher and this is often the path taken by authorities and sometimes researchers but maybe authorities and researchers are also part of the problem. The next section will briefly consider this proposition.

\section{Stop Blaming the Cook and Fix the Kitchen}

If a restaurant has a cook that is producing poor meals then the cook is either fired or is mentored by an experienced chef and sometimes sent for further training. It may also involve changing the kitchen if it is part of the problem.

A good deal of the early research into mathematics pedagogy was based upon a variety of assumptions. A common one was that teachers developed characteristic patterns of behaviour depending upon their classroom situation. These patterns may have been conscious and deliberately chosen, or have arisen from experience and may have been largely unreflected and unconscious. Such teaching patterns were often designated as orientations, styles or modes of teaching.

Many researchers represented teaching styles upon a continuum with their theoretical opposites as end points. Some researchers used more than one continuum. The aim of this type of research was either to present an overall structure for current teaching practice 
according to the researcher's theoretical presentation, or to categorise teachers according to a particular theoretical orientation. The assumption was that all teachers could be located somewhere along the continuum.

For example, Brady (1985) investigated this area of research and concluded that all the models could be placed upon a series of continuums with the end-points being: (a) teacher centred intentions and behaviour; and (b) child centred intentions and behaviour. A major criticism of Brady's models was that the classification of teaching behaviour or intention by assigning them to a position upon the continuum did little to explain the totality of teacher classroom behaviour.

Another modern example of this type of research can be found in the following study which stated that:

To identify the extremes of teachers' beliefs and to facilitate categorisation of responses, an artificial continuum of teaching and learning was used. At one end of this continuum, mathematics is seen as a fixed body of facts to be delivered by teachers and internalised by students. Referred to as a traditional teaching approach, this perspective is associated with individual student work, rehearsal of routine questions, and reliance on textbooks or worksheets. This view may be accompanied by a belief that problem solving is an end and that problems should be presented to students after they have mastered basic facts and skills. At the other end of the continuum, termed a contemporary teaching approach, mathematics is seen as a dynamic subject to be explored and investigated. Classroom practices associated with this perspective usually involve group work and the use of nonroutine questions that promote mathematical thinking, and the development of problemsolving skills. This teaching approach may be accompanied by a belief that problem solving is a means to learning mathematics (Anderson, Sullivan \& White, 2004, p. 40).

In this example there is an unstated but automatic assumption that student centred pedagogy (or problem solving) is always best. Yet this is too simplistic and ignores the cases of student centred pedagogy existing in a classroom that is intellectually undemanding or empty of cognitive challenge. Using a food analogy, the equivalent is to categorise all humans on a continuum of 'hamburger eaters' and 'not hamburger eaters'. All people must fit along this continuum. Thus some people may gorge themselves on fast foods whereas others are the consumers of healthier alternatives. How useful is this continuum in reflecting what people really eat? How useful is it helping people to change?

Being labelled as 'teacher centred' comes with a significant amount of shame. It usually carries the stigma of being a teacher who does not care for their students. Just as the label 'burger eaters' may attract the stigma of 'unhealthy slobs'. This sort of labelling hardly contributes to an enlightening debate. It is time for research to stop calling teachers names and to help them to develop cognitively challenging classrooms. The classroom teacher who uses thecognitive emptying/elicitation/exposition strategy does so because he or she believes that this is the best way of assisting student learning. It is these beliefs that must be exposed and challenged before the classroom teacher is likely to change strategies. 
This section has briefly considered how teaching strategies can starve the brain damaging learning outcomes and how they can be designed to exercise and develop the brain. The brain is a muscle and the more it is used the better it works. Teaching strategies that deliver brain food in the form of stimulation, exercise and challenge are needed in today's mathematics classrooms.

Is there only one best way of teaching or cooking or are there many ways? The next section will briefly consider this proposition.

\section{A Collection of Recipes or Pedagogical Repertoires}

In 1952 Cunday and Rollett stated that "Mathematics is often regarded as the bread and butter of science. If the butter is omitted, the result is indigestion, loss of appetite, or both" (cited in Ollerton, 2003, p. 57). Does the lack of one ingredient destroy the final dish? A good chef knows that the success of the final dish depends upon the way the individual ingredients work as a whole. For the teacher it is the same realisation that everything is connected.

There is a need to dismiss the assumption that mathematics classroom teachers use only one pedagogical style within their classroom or for that matter in any one lesson. The context of the mathematic classrooms and the pedagogical strategies employed within the classrooms are more complex than a mere choice between two extremes. Major longitudinal research coming from Singapore has revealed that experienced and successful teachers continually vary their approach where they 'weave' a number of different pedagogical strategies into their classroom (Luke, 2005). This seems to resonate with the popular expression: variety is the spice of life.

Thus the Singaporean teachers present a healthy diet to the class by varying the ingredients according to the conditions. A mathematics teacher doesn't adopt one approach and stick to it, but rather adjusts the pedagogy to the multitude of variables that influence the classroom context in order to create conditions favourable to student learning including cognitive challenge and meaning construction.

\footnotetext{
Creating such conditions requires the teacher to recognize when it is useful to intervene, when to be strongly didactic, when to offer hints and advice and when to stand back and strategically decide not to 'interfere'. Seeking to offer students choice in their learning inevitably means finding problems that encourage students to make decisions about how to proceed and about what approaches and what resources they might use in order to work towards a solution (Ollerton, 2003, p. 98).
}

Thus the teachers must be assisted by researchers and authorities to develop a rich repertoire of teaching strategies and challenging tasks in order to deliver brain food in the form of stimulation, exercise, challenge and meaning. It is the function of symposiums such 
as this one to assist in the transformation of research into practice by working towards joyful and meaningful mathematics.

When food is prepared, the way it is eaten has important outcomes. A person can shovel the food down as quickly as possible or the person can concentrate upon the food and savour the tastes and sensations. While both actions may sustain the body, it is the second that will long be remembered and treasured. Does the same apply to mathematics education? This proposal will be briefly considered in the next section.

\section{Engagement and Intensity}

The fast food industry has long understood the value of engagement and uses many promotional strategies to attract people to their products such as product identification (some unique symbol or character), free give away prizes (usually toys to engage the pester power of children), many advertisements that are colourful, lively and target peoples desires for happiness, freedom and having a good time, and finally they use bright, clean, lively premises staffed with happy smiling young faces. So, because of these marketing strategies the attraction is strong, but engagement is something much deeper.

Engagement in mathematics is important in mathematics because it is argued that decreased engagement can have negative effects on students' lives(Sullivan, Mousley, \& Zevenbergen, 2005). One of my colleagues (Attard, 2010, 2011a, b, 2012) conducted a longitudinal case study investigating the problem of lowered engagement with mathematics using the students' perspectives of the factors that influenced their engagement during the middle years of schooling within an Australian setting. The study spanned three school years. The study used a multi-dimensional view of engagement which occurs with the meeting of all three facets; cognitive, operative and affective, that leads to students valuing and enjoying school mathematics and seeing connections between school mathematics and their own lives beyond the classroom(Fair Go Team, NSW Department of Education \& Training, 2006; Munns \& Martin, 2005).

One finding that is worth repeating is in regard to having fun in mathematics classrooms. The data clearly revealed the aspects of lessons that made them fun were not always based on games but involved relevance to the students' lives, an element of challenge built into the tasks, and the ability for students to see the mathematics as useful within practical situations. As in the first section of this paper, students need cognitive challenge, to be able to construct meaning through the relevance and applicability of the mathematics. Lessons that promoted affective, operative and cognitive engagement with mathematics were regarded as fun. It is within this context that brain research can also add some interesting research findings. 
Brain research has found that the speed at which we think is also plastic. It is possible to train the brain to fire brain neurons more quickly in response to stimuli. The essence of the training lay in paying close attention.

Merzenich discovered that paying close attention is essential to long-term plastic change. In numerous experiments he found that lasting changes occurred only when his monkeys paid close attention. When animals performed tasks automatically, without paying attention... the change did not last. We often praise "the ability to multitask." While you can learn when you divide your attention, divided attention doesn’t lead to abiding change in your brain (Doidge, 2008, p. 68).

So it seems that the intensity of engagement is the key for stimulating the control centre to produce acetylcholine (helps concentration) and dopamine (pleasure).

\footnotetext{
That's why learning a new language in old age is so good for improving and maintaining the memory generally. Because it requires intense focus, studying a new language turns on the control system for plasticity and keeps it in good shape for laying down sharp memories of all kinds (Doidge, 2008, p. 87).
}

So the classical education of the 1850s to the 1900s involving the learning of other languages and the demands upon students to pay close attention to their hand writing, speech and pronunciation all played a part in developing the capacities of the brain.

Now during a 40 minute lesson, brain research has found that there are optimal times when students are more open to paying close attention. We tend to remember best what comes first and second best what comes last and this is known as the primacy-recency effect. In other words there are windows of time for teachers when there is a learning opportunity that is best for new material because the students are more predisposed to pay close attention. In the figure below, these windows for learning and retaining new material are shown.

\section{Retention During a Learning Episode}

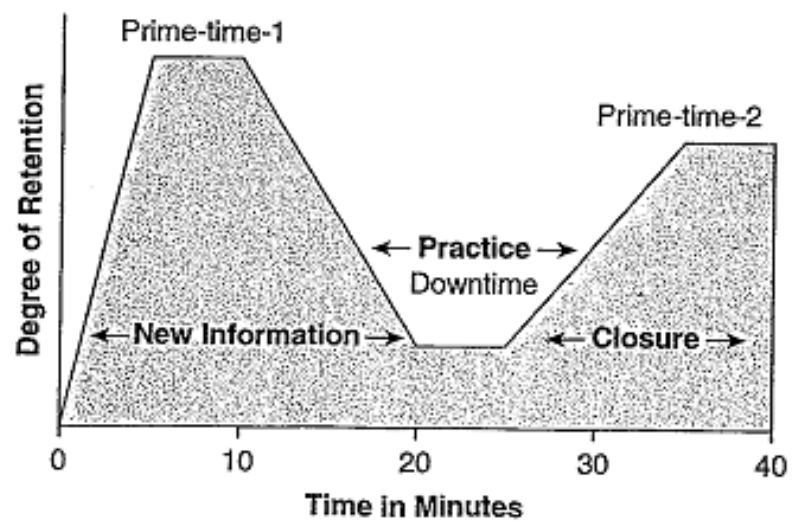

Figure 1. New information can be presented in prime time 1, closure in prime time 2 and practice is appropriate in the downtime. (Sousa, 2008, p. 61). 
Just as there seems to be times when people are hungrier for food than at other times, so it seems that there are times when it is best to challenge students with new material and other times when they would be best doing drill and practice.

Now on the surface the importance of intensity may sound like it is supporting the practice of cramming for an examination. Yet students will tell you that cramming for an examination usually results in what has been memorised is lost within a week or two afterwards. This seems a contradiction.

Firstly, the intensity principle is referring to the learning of new material, which I suspect for some crammers may also be true. Secondly, for retention the new material would need a period of practice. There is a distinction made in the literature between massed practice and distributed practice (Sousa, 2008). Cramming is an example of massed practice where material is crammed into the working memory, but will be quickly dropped or forgotten without sustained practice. The material has no further meaning or need for longterm retention. Distributed practice on the other hand is sustained practice over time resulting in long-term storage.

Now all education systems formulate ways of giving feedback to the students in order to communicate both the desired system outcomes and the student's progress towards meeting these outcomes. In the next section, this will be briefly explored.

\section{Student Feedback}

When dealing with food, a cook is quickly informed about the customer's satisfaction with the meal. Walking out without paying the bill sends a strong message. Good cooks adjust their cooking to suit the tastes of their customers. Parents quickly become attuned to the various likes and dislikes of their children. Usually the feedback is directed at the food and not at the cook, but positive feedback encourages the cook to do better.

Early behaviourism studies used stimulus response experiments and relied on rewards and punishments to change behaviour. This was also adopted into teaching strategies and involved using differing feedback strategies to promote behaviour modification, usually with an emphasis on punishments such as hitting with a cane or keeping students in after school. While behaviourism was unable to satisfactorily explain why this seemed to be mostly effective, brain research is able to deepen our understanding of the processes involved.

The, Fast For Word brain training program mentioned earlier consists of seven brain exercises that were developed from the latest brain research. It has had remarkable success with language-impaired and learning-impaired children including autistic children. A reward is a crucial feature of the program because each time the child receives a reward the brain secretes neurotransmitters such as dopamine and acetylcholine which helps consolidate the brain changes the child has made. Dopamine reinforces the reward while acetylcholine helps concentration and sharpens the memory. 
The program which is a series of plasticity based techniques has

... helped hundreds of thousands. Fast ForWord is disguised as a children's game. What is amazing about it is how quickly the change occurs. In some cases people who have had a lifetime of cognitive difficulties get better after only thirty to sixth hours of treatment (Doidge, 2008, p. 47).

Research into technology and the use of digital games has focussed on extending the thinking of students, particularly in literacy and numeracy and upon using levels and rewards as a means of providing feedback to the student. For example, Lowrie (2005) worked with eight-year old students using the Pokemon environment and found that the children worked well beyond the experiences being provided in the standard school curriculum in terms of spatial representation and visualisation. This work highlighted the possibilities of the digital games environment for enhancing mathematical learning and understandings that were beyond the realms of standard pencil-and-paper representations.

This is the last section of my smorgasbord of the wonderfully rich, internationally flavoured, mathematics education research. It is time to bring all the sections together.

\section{Conclusion}

The sign of a good meal is that the consumer is left with the desire to have more, to repeat the experience at another time. I hope this paper has had the same effect.

Brain research is still in its infancy regarding applications to teaching and learning but what has already arisen has added to our understanding. We now have a better understanding of the effect of education upon students and the realisation that the brain requires nourishment, because the saying, use it or lose it applies to every student in every mathematics classroom.

\footnotetext{
... post-mortem examinations have shown that education increases the number of branches among neurons. An increased number of branches drives the neurons farther apart, leading us to an increase in the volume and thickness of the brain. The idea that the brain is like a muscle that grows with exercise is not just a metaphor (Doidge, 2008, p. 43).
}

Cognitively well-nourished mathematics students are the result of a rich and varied diet of challenging, meaningful and rewarding classroom experiences. Recipes that are unhealthy should be removed. Using too much salt is just as unhealthy as using cognitive emptying recipes in the classroom. Teachers must resist becoming mere packet warmers by some educational administrators and systems and seek to adapt international programs rather than just copy.

So I conclude upon a hopeful note. This symposium fills me with hope. It is evident in the desire and passion of the mathematics teacher chefs who give freely of their time to attend. And it is through this collective power via the Regional Centre for Quality Improvement of Teachers and Educational Personnel (QITEP) in Yogyakarta that I feel the mathematics education profession will demand more than just 'microwave warming' 
solutions that are on offer from other countries. It is my hope that this symposium will assist all participants in transforming research into practice by integrating the best of global mathematics education practices with their own successful teaching and learning practices to produce joyful and meaningful mathematics.

\section{Post Script}

An assumption of this paper is that mathematics provokes hunger, passion and desire in teachers and students. Hopefully the staffrooms of mathematics teachers are kitchens of delight staffed by passionate experts that inspire the students. What follows is a very unique but interesting and delightful understanding of the number system.

The famous Danish writer, Peter Høeg is one student who was inspired by his mathematics teachers. In one of his now famous novels he has the lead female character named Smilla trying to explain her 'sense of snow' using mathematics to a man living below her apartment. It fits loosely with the theme of this paper as the man is doing the cooking (making it a fantasy tale for some female readers?). The extracts from the novel are shown in italics (Høeg, 1992, pp. 121-122) and I have added some remarks that appear in normal script.

To set the scene, the male (who is a government operative) lives in a ground floor apartment and has been watching this attractive girl from Greenland (who has been making some uncomfortable enquiries involving the government) pass by his door each day. Finally, he has invited her in for dinner, and while he cooks, they chat and she tells him of her love of ice, snow and mathematics. Her description may challenge your own view of the number system, at the very least I hope it will cause you to look at numbers in a different way.

It begins with the Smilla, saying:

Do you know what the foundation of mathematics is?' ... 'The foundation of mathematics is numbers. If anyone asked me what makes me truly happy, I would say: numbers. Snow and ice and numbers. And do you know why?

How to answer such a question? How could he respond without making a fool of himself? So,

he splits the claws with a nutcracker and pulls out the meat with curved tweezers.

Undaunted by his silence she continues,

Because the number system is like human life. First you have the natural numbers. The ones that are whole and positive. The numbers of a small child. But human consciousness expands. The child discovers a sense of longing, and do you know what the mathematical expression is for longing?

Obviously he is a strong silent type because

he adds sour cream and several drops of orange juice to the soup. She continues, The negative numbers. The formalization of the feeling that you are missing something. And human consciousness expands and grows even more, and the child discovers the in between spaces. 
Between stones, between pieces of moss on the stones, between people. And between numbers. And do you know what that leads to? It leads to fractions. Whole numbers plus fractions produce rational numbers. And human consciousness doesn't stop there. It wants to go beyond reason. It adds an operation as absurd as the extraction of roots. And produces irrational numbers.

Having decided that silence is his best strategy,

he warms French bread in the oven and fills the pepper mill. She continues It's a form of madness. Because the irrational numbers are infinite. They can't be written down. They force human consciousness out beyond the limits. And by adding irrational numbers to rational numbers, you get real numbers. continues,

She notices that he seems to be listening (although still saying nothing), so she

It doesn't stop. It never stops. Because now, on the spot, we expand the real numbers with imaginary square roots of negative numbers. These are the numbers we can't picture, numbers that normal human consciousness cannot comprehend. And when we add the imaginary numbers to the real numbers, we have the complex number system. The first number system in which it's possible to explain satisfactorily the crystal formation of ice. It's like a vast, open landscape. The horizons. That is Greenland, and that's what I can't be without!

There is a long silent pause and now what does a typical male do in such a situation? He is confronted with a beautiful woman bearing her soul, exposing her innermost feelings to him. He cannot remain silent and do nothing so what is he to do?

'Smilla,' he says, 'can I kiss you?'

Disappointed at this ending my students suggested an alternative suggestion

'Ok, Smilla, your number is up!'

\section{References}

Anderson, J., Sullivan, P., \& White, P. (2004). The influence of perceived constraints on teachers' problem-solving beliefs and practices. In I. Putt, R. Faragher, \& M. McLean (Eds.), Mathematics education for the third millennium: Towards 2010 (Proceedings of the 27th annual conference of the Mathematics Education Research Group of Australasia, pp. 39-46). Townsville QLD: MERGA

Attard, C. (2010). Students' experiences of mathematics during the transition from primary to secondary school. Paper presented at the 33rd annual conference of the Mathematics Education Research Group of Australasia, Fremantle, Perth.

Attard, C. (2011a). Engagement with mathematics: The influence of teachers. Southeast Asian Mathematics Education Journal, 1(1), 31-39.

Attard, C. (2011b). "My favourite subject is maths. For some reason no-one really agrees with me": Student perspectives of mathematics teaching and learning in the upper primary classroom. Mathematics Education Research Journal, 23(3), 363-377.

Attard, C. (2012). The influence of pedagogy on student engagement with mathematics during the middle years of schooling. In A. L. White \& U. H. Cheah (Eds.), Transforming School Mathematics Education in the 21st Century (pp. 140-157). Penang: SEAMEO RECSAM 
Baba, T. (2007). How is lesson study implemented? In M. Isoda, M. Stephens, Y. Ohara \& T. Miyakawa (Eds.) (2007). Japanese lesson study in mathematics: Its impact, diversity and potential for educational improvement (pp. 2-7). Singapore: World Scientific Pub., Co.

Brady, L. (1985). Models and methods of teaching. Parramatta, Sydney: Prentice Hall.

Brousseau, G. (1984). The crucial role of the didactical contract in the analysis and construction of situations in teaching and learning mathematics. In H. G. Steiner (Ed.), Theory of mathematics education (pp. 110-119). Bielefeld, Germany: Universität Bielefeld.

Clements, M. A. (2003). Professional practice in mathematics education: Introduction. In A. J. Bishop, M. A. Clements, C. Keitel, J. Kilpatrick, \& F. Leung (Eds.), Second international handbook of mathematics education (pp. 637-641). Dordrecht, The Netherlands: Kluwer Academic Publishers.

Clements, M. A. (2004). Pre-service Teacher Education: Its time for a rethink. Keynote address delivered at the EduCATE 2004 Conference organized by the Faculty of Cognitive Sciences and Human Development (UNIMAS) in collaboration with the Bahagian Pendidikan Guru (Kementerian Pelajaran Malaysia). Kuching Sarawak Malaysia.

Doidge, N. (2008). The brain that changes itself: Stories of personal triumph from the frontiers of brain science (Revised Edition).Melbourne: Scribe Publications Pty Ltd.

Fair Go Team NSW Department of Education and Training. (2006). School is for me: pathways to student engagement. Sydney: NSW Department of Education and Training, Sydney, Australia.

Høeg, P. (1992). Smilla's Sense of Snow. New York: Dell Publishing.

Leung, F. K. S. (2012). What can and should we learn from international studies of mathematics achievement? In J. Dindyal, L. P. Cheng \& S. F. Ng (Eds.), Mathematics education: Expanding horizons, (Proceedings of the 35th annual conference of the Mathematics Education Research Group of Australasia, eBook,, pp. 34-60). Singapore: MERGA Inc.

Lowrie, T. (2005). Problem solving in technology rich contexts: Mathematics sense making in out-of-school environments. Journal of Mathematical Behavior, 24, 275-286.

Luke, A. (2005). Making new Asian pedagogies: Classroom interaction in Singapore classrooms. Keynote address for Redesigning Pedagogy: Research, Policy, Practice (The first international conference on educational research).Singapore: National Institute of Education.

McIntosh, A. (2003). A typical Australian Year 8 mathematics lesson. In H. Hollingsworth, J. Lokan \& B. McCrae (2003). Teaching mathematics in Australia: Results from the TIMSS Video Study (pp. 106-108). Camberwell, Australia: Australian Council for Educational Research.

Ministry of Education (MOE)(2007). Ministry of Education Mathematics Syllabus - Primary, Singapore: Curriculum Planning and Developmental Division.

Munns, G., \& Martin, A. J. (2005). It's all about MeE: A motivation and engagement framework. Paper presented at the Australian Association for Academic Research Focus Conference, Cairns.Retrieved 28 September 2012 from http://www.aare.edu.au/05pap/mun05400.pdf

Ollerton, M. (2003). Getting the buggers to add up. London: Continuum.

Skemp, R.R. (1976). Relational understanding and instrumental understanding. Mathematics Teaching, 77, 20-26.

Sousa, D. A. (2008). How the brain learns mathematics. Thousand Oaks, CA: Corwin Press.

Sullivan, P., Mousley, J., \& Zevenbergen, R. (2005). Increasing access to mathematical thinking. The Australian Mathematical Society Gazette, 32(2), 105-109. 
White, A. L. (2011). School mathematics teachers are super heroes.South East Asia Mathematics EducationJournal, 1(1), 3-17.

White, A. L.,\& Lim, C. S. (2008). Lesson study in Asia Pacific classrooms: Local responses to a global movement. ZDM The International Journal of Mathematics Education,40 (6), 915-925. 